\title{
Thrombin Causes Neuronal Atrophy and Acute but not Chronic Cell Death
}

\author{
Jayalakshmi Caliaperumal, Sonia Brodie, Yonglie Ma, Frederick Colbourne
}

\begin{abstract}
Background: Brain injury after intracerebral hemorrhage (ICH) arises from numerous contributors, of which some also play essential roles. Notably, thrombin production, needed to stop bleeding, also causes acute cell death and edema. In some rodent models of ICH, peri-hematoma neurons die over weeks. Hence we evaluated whether thrombin is responsible for this chronic degeneration. Functional impairments after ICH also result from sub-lethal damage to neurons, especially the loss of dendrites. Thus, we evaluated whether thrombin infusion alone, a reductionist model of ICH, causes similar injury. Methods: Adult rats had a modest intra-striatal infusion of thrombin $(1 \mathrm{U})$ or saline followed by a behavioral test, to verify impairment, 7 days later. After this they were euthanized and tissue stained with Golgi-Cox solution to allow the assessment of dendritic morphology in striatal neurons. In a second experiment, rats survived 7 or 60 days after thrombin infusion in order to histologically determine lesion volume. Results: Thrombin caused early cell death and considerable atrophy in surviving peri-lesion neurons, which had less than half of their usual numbers of branches. However, total tissue loss was comparable at $7\left(24.1 \mathrm{~mm}^{3}\right)$ and 60 days $\left(25.6 \mathrm{~mm}^{3}\right)$. Conclusion: Thrombin infusion causes early cell death and neuronal atrophy in nearby surviving striatal neurons but thrombin does not cause chronic tissue loss. Thus, the chronic degeneration found after ICH in rats is not simply and solely due to acute thrombin production. Nonetheless, thrombin is an important contributor to behavioral dysfunction because it causes cell death and substantial dendritic injury.
\end{abstract}

RÉSUMÉ: La thrombine cause une atrophie neuronale et une mort cellulaire aiguë mais ne cause pas de mort cellulaire chronique. Contexte: De nombreuses variables contribuent, parfois d'une manière essentielle, à l'étendue des effets au cerveau à la suite d'une hémorragie intra-cérébrale (HIC). Notamment la production de thrombine, nécessaire pour arrêter le saignement, provoque également la mort cellulaire aiguë et l'œdème. Dans certains modèles d'HIC du rongeur, les neurones péri- hématomes meurent au cours des semaines. Par conséquent nous avons évalué si la thrombine est responsable de la dégénérescence chronique. Des déficiences fonctionnelles suivant une HIC entraînent également des effets sublétaux chez les neurones, surtout la perte des dendrites. Ainsi nous avons testé si la thrombine seule cause un effet similaire. Méthodes: Nous avons administré aux rats adultes une infusion intra-striatale modeste ou de thrombine $(1 \mathrm{U})$ ou d'une solution saline, avec un test de comportement sept jours plus tard pour vérifier la déficience. Ils ont étaient euthanasiés et nous avons fait une évaluation morphologique des neurones striataux, suivant l'imprégnation avec la méthode de Golgi-Cox. Dans une autre expérience, les rats qui ont survécu entre 7 ou 60 jours après l'infusion de thrombine afin de déterminer le volume des lésions histologiques. Résultats: La thrombine a causé la mort précoce des cellules at une atrophie considérable de neurones péri-lésions survivants, gardant seulement la moitié de leurs branches. Toutefois, la perte de tissus était comparable à 7 jours $(24.1 \mathrm{~mm} 3)$ et à 60 jours $(25.6 \mathrm{~mm} 3)$. Conclusion: L'infusion de thrombine cause la mort cellulaire précose et l'atrophie des neurones dans les neurones striataux survivants voisinants, mais la thrombine ne cause pa la perte de tissus. Alors la dégénérescence chronique suivant une HIC chez les rats n'est pas seulement dûe à la production aiguë de la thrombine. Néanmoins, la thrombine contribue d'une façon importante au dysfonctionnement comportemental, car elle provoque la mort cellulaire et atteint les dendrites des neurones péri-lésions.

Keywords: Stroke, intracerebral hemorrhage, thrombin, neurodegeneration, striatum

doi:10.1017/cjn.2014.105

Can J Neurol Sci. 2014; 41: 714-720

Stroke is one of the leading causes of death and disability in Canada. About $10-15 \%$ of strokes are caused by intracerebral hemorrhage (ICH), which has a higher mortality rate than ischemic strokes. ${ }^{1}$ Survivors of an ICH are often left with significant neurological impairments and functional disabilities. ${ }^{1,2}$ Accordingly, numerous animal and clinical studies have focused on the nature, timing and mechanisms of injury after ICH in an effort to develop neuroprotective therapies. These inevitably target one or more of the many mechanisms of secondary degeneration, because the primary damage from an $\mathrm{ICH}$, blood dissecting through tissue, is not amenable to 'neuroprotection' per se. ${ }^{3}$

Animal models documenting the time course of injury reveal considerable peri-hematoma cell death in the days after an $\mathrm{ICH}^{4-6}$ By infusing collagenase, an enzyme that damages the basal lamina of blood vessels resulting in bleeding over hours, we showed significant tissue loss even weeks after the initial bleed, ${ }^{5,6}$ similar to what occurs in patients. ${ }^{7}$ Besides this, surviving peri-hematoma neurons sustain structural damage that would also contribute to functional impairments. Notably, peri-hematoma neurons show considerable dendritic atrophy after an ICH in rat, ${ }^{6}$ which probably occurs from mechanical trauma as well as secondary degenerative processes.

Numerous mechanisms contribute to secondary damage. The release of ferrous iron from degrading erythrocytes and its

From the Center for Neuroscience (JC, FC); Department of Psychology (SB, YM, FC), University of Alberta, Edmonton, Alberta.

Received July 25, 2014. Final Revisions Submitted October 15, 2014. Correspondence to: Frederick Colbourne, P217 Biological Sciences Building, Department of Psychology, University of Alberta, Edmonton, AB, Canada, T6G 2E9. E-mail: fcolbour@ualberta.ca 
consequences has received considerable attention. Studies show a steady increase in non-heme iron levels over a week that persists in the brain. ${ }^{8-10}$ This 'free' iron catalyzes free radical reactions, thereby causing cell death, blood brain barrier damage and edema. ${ }^{11}$ Given the time course of iron liberation, the fact that it persists in the brain for a long time and because many studies show that iron chelators limit brain injury in animal models of $\mathrm{ICH}^{11}{ }^{11}$ we tested whether an infusion of iron $\left(\mathrm{FeCl}_{2}\right)$ would cause peri-lesion dendritic damage and chronic tissue loss as seen in the collagenase ICH model. Both effects occurred in this simplified model, ${ }^{12}$ suggesting that iron release after an ICH has similar effects.

In the current study, we evaluated whether thrombin has similar harmful effects because it is also considered a major contributor to secondary damage. Thrombin, a blood-derived serine protease, is generated quickly to stop bleeding after an ICH begins. Thus, it is not surprising that thrombin is abundantly present after $\mathrm{ICH},{ }^{13}$ However, as with iron infusions, thrombin also causes neuronal cell death, blood brain barrier damage, edema and behavioral dysfunction, which are amenable, at least in animal models, to inhibitors such as hirudin and argatroban. ${ }^{11,13-16}$ The effects of thrombin are mediated by protease-activated receptors (PAR), especially PAR1, which are found on neurons and astrocytes. ${ }^{11,14,16}$ Interestingly, lower doses of thrombin can be neuroprotective. In vitro studies show that thrombin protects rat astrocytes and hippocampal neurons from oxidative stress and hypoglycemia induced cell death, ${ }^{17,18}$ whereas in vivo studies have shown that pretreatment using a low dose of thrombin infusion prevents cell damage induced by a large dose of thrombin. ${ }^{19}$ Low doses of thrombin also stimulate neurogenesis and angiogenesis, which may improve recovery after $\mathrm{ICH}^{20}$

In the current study we used an intra-striatal infusion of thrombin, ${ }^{21-23}$ a simplified and commonly used model, to test the role of thrombin in causing behavioral deficits, dendritic atrophy, and early and late tissue loss. We used a moderate dose of thrombin so that it would reflect the low end of the range in damage commonly used in rat $\mathrm{ICH}$ studies and so that a sufficient amount of striatum remained to allow sampling of enough neurons in the peri-lesion zone. We used the Golgi-Cox stain, which is a well-established method of examining dendritic arborization. It was predicted that thrombin would cause dendritic damage in surviving striatal neurons from the peri-lesion zone. This same dose of thrombin was also used to produce a lesion that was histologically quantified at 7 and 60-day survival times. We hypothesized that protracted neuronal death would occur, leading to significant increase in tissue lost over time.

\section{Material AND MethodS}

\section{Animals}

All procedures followed the guidelines of the Canadian Council of Animal Care and were approved by the Biosciences Animal Care and Use Committee at the University of Alberta. We used 80 male Sprague - Dawley rats (250-350 g, approximately three months old) obtained from the Biosciences animal colony at the University of Alberta. Twenty were used in the first experiment whereas 34 were used in the second experiment. An additional 26 rats were used in pilot experiments (e.g., to evaluate doses by confirming acute cell death, edema, etc. - data not shown).

Rats were randomly assigned and we used blinded assessment. Animals were single housed in standard polycarbonate cages (wood chip bedding). Single housing was used to avoid the influence of social housing on dendritic morphology and potentially on cell death. Food (Purina rodent chow) and water were provided $a d$ lib and rats were kept in a temperature- and humidity-controlled room (lights on from seven am - seven pm).

\section{Surgery}

Surgical procedures were performed aseptically. Rats were anesthetized with isoflurane (4\% induction, $1.5-2.5 \%$ maintenance in $60 \% \mathrm{~N}_{2} \mathrm{O}$, balance $\mathrm{O}_{2}$ ). Body temperature was measured with a rectal probe and maintained at $37^{\circ} \mathrm{C}$ during anesthesia with a heated water blanket. After placing the animal in a stereotaxic frame a hole was drilled $3.5 \mathrm{~mm}$ right and $0.2 \mathrm{~mm}$ anterior to Bregma. A 26-gauge needle (Hamilton, Reno, NV) was inserted $6.5 \mathrm{~mm}$ from the skull surface into the striatum to infuse $30 \mu \mathrm{L}$ of saline or saline containing $1 \mathrm{U}$ of rat thrombin (Sigma, \#T5772) over 10 minutes using an infusion pump. After a 10-minute wait, the needle was slowly removed. A small metal screw was inserted in the hole, bupivacaine was applied to the skin, and clips were used to close the wound. Note that the infusion location matched our previous work for collagenase and iron infusions. ${ }^{5,10,12}$

\section{Corner Turn Test (Experiment 1 only)}

Turning bias was measured by repeatedly placing rats in front of two angled Plexiglas walls (41 cm in height; $30.5 \mathrm{~cm}$ in length) placed at $30^{\circ}$. The number of times out of ten trials the rats turned in a given direction was counted - it is known that rats with striatal injury tend to turn to the side of the injury. ${ }^{24}$ Testing was done on the day prior to surgery and at seven days post-surgery, shortly before euthanasia.

\section{Golgi-Cox Staining (Experiment 1 only)}

Saline $(n=9)$ and thrombin $(n=11)$ infused rats were euthanized $(100 \mathrm{mg} / \mathrm{kg}$ intraperitoneal pentobarbital) at seven days after ICH surgery and the tissue was processed for Golgi-Cox staining and analysis according to established procedures, ${ }^{25}$ which we used previously. ${ }^{6,12,26}$ Briefly, rats were transcardially perfused with saline and brains were removed and immersed in Golgi-Cox solution for 14 days. Then $200 \mu \mathrm{m}$ thick sections were cut on a vibrating microtome (Leica VT 1200S). Five to six medium spiny neurons (averaged) in the peri-insult and contralateral striatum were chosen and drawn from each animal ( $20 \times$ objective for camera lucida). These neurons were all clearly stained with no obstruction by blood vessels or loss of dendrites through sectioning. Sholl analysis and branch order analysis was performed, which estimates the dendritic length and branch complexity, respectively. The distance from the cell body to the edge of the lesion was also estimated (peri-lesion cells only).

Lesion volume was not measured in this experiment because the thick sections used for Golgi-Cox staining and the nature of the staining would have made any determination of lesion size difficult and inaccurate.

\section{Lesion Volume (Experiment 2 only)}

At $7(n=15)$ and 60 days $(n=15)$, thrombin infused rats were euthanized with pentobarbital $(100 \mathrm{mg} / \mathrm{kg} \mathrm{IP})$ and transcardially perfused with $0.9 \%$ saline, then formalin. An additional four rats were infused with the same dose of thrombin, which had been 
previously heated to $95^{\circ} \mathrm{C}$ for one hour (i.e., heat inactivated) and these animals were humanely euthanized at seven days. We did not use additional saline control groups because we have repeatedly found that a saline infusion does not cause brain injury, other than a small needle track, even at long survival times. ${ }^{27,28}$ Coronal $40-\mu \mathrm{m}$ thick frozen sections were cut at $200 \mu \mathrm{m}$ intervals and stained with Cresyl Violet. An experienced investigator determined lesion volume with NIH ImageJ software (National Institutes of Health, Bethesda, Maryland, USA) on digitized images of coronal brain sections. These were taken so that they extended from anterior, through and beyond the sections with obvious tissue damage or ventricular dilation. ${ }^{6,12,26}$ Besides the cavity and dilated ventricle, brain injury was visually identified as darkly stained areas that correspond to degenerating tissue and inflammation when viewed in a microscope. The volume of tissue lost was calculated as:

Tissue lost $\left(\mathrm{mm}^{3}\right)=$ volume of normal hemisphere - volume of injured hemisphere.

Hemisphere volume $=$ average (area of the complete coronal section of the hemisphere - area of ventricle - area of damage if any) $\times$ interval between sections $\times$ number of sections.

\section{Statistical Analysis}

Data are presented as mean \pm standard deviation (SD) and were analyzed by analysis of variance (ANOVA, SPSS v.17.0, SPSS Inc, Chicago, IL). Distance between the cell body (Golgi-Cox study) and lesion edge was also correlated (Pearson $r$ value).

\section{RESUlts}

\section{Exclusions}

One rat from Experiment 2 died unexpectedly during surgery of unknown cause. There were no other unplanned mortality or exclusions in Experiment 1 or 2.

\section{Experiment 1}

A repeated-measures ANOVA on the corner turn test (Fig. 1) revealed a significant time effect (baseline and day seven, $\mathrm{p}<0.001)$, time by group interaction $(\mathrm{p}=0.002)$ but no group effect (saline and thrombin, $\mathrm{p}=0.07$ ). As expected, baseline scores were normal $(\sim 50 \%)$ and not significantly different between groups $(p=0.264)$ whereas thrombin caused a significant turning bias at day seven post-infusion $(\mathrm{p}<0.001 \mathrm{vs.}$ baseline, and $\mathrm{p}=0.003$ vs. saline). The saline controls had similar scores across time $(\mathrm{p}=0.777)$ indicating that the saline infusion did not alter behavior on this test, as expected.

Golgi-Cox stained striatal neurons surrounding the saline infusion site appeared normal (Fig. 2A, B) and similar to cells in the contralateral striatum. Conversely, the neurons in the peri-lesion zone of thrombin infused rats were markedly atrophied (Fig. 2C, D) and unlike the normal appearing cells on the contralateral side. Dendritic length was quantified with the Sholl analysis and it showed significant peri-lesion dendritic injury (Fig. 3A, p <0.001 vs. ipsilateral saline neurons and vs. contralateral neurons of the thrombin group). The extent of atrophy was related to distance from the lesion, with those cells closest to the lesion showing the greatest dendritic injury $(r=0.405$, $\mathrm{p}=0.002$ ). Dendrites of neurons around the saline infusion were slightly but not significantly shorter than contralateral neurons

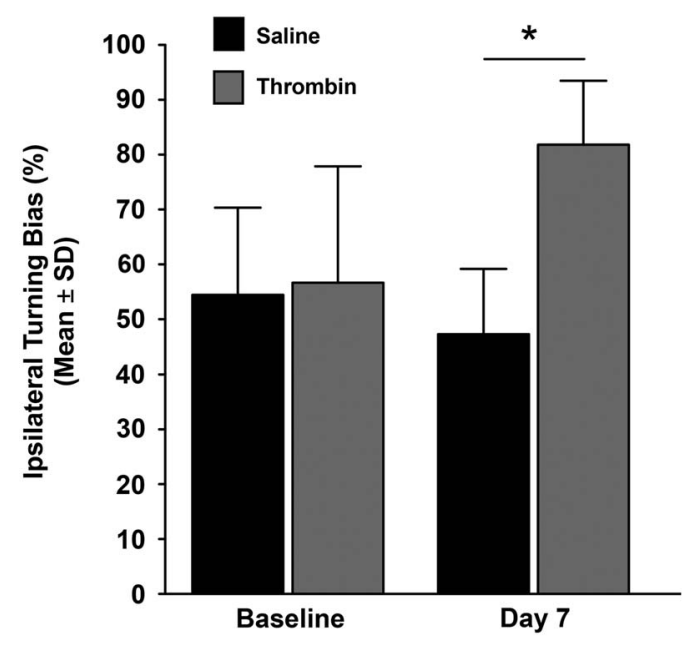

Figure 1: Turning prior to (baseline) and following the infusion of thrombin $(1 \mathrm{U})$ or saline into the striatum. Scores were similar at baseline and near the expected 50\% (normal). At day 7, the thrombininfused rats had a significant bias to turn towards to side of the lesion $\left({ }^{*} p<0.05\right)$.

$(p=0.054)$. However, neurons on the contralateral side of thrombin infused rats were slightly and significantly shorter ( $p=0.019$ vs. saline). For the branch order analysis (Fig. 3B, C), which reflects dendritic complexity, we found rats in the thrombin group had significantly fewer branches on ipsilateral striatal neurons compared to saline group (for orders 1-5: $\mathrm{p}<0.001 ; 6$ : $p=0.011)$. The 7 th order branch was near zero in most cases and thus was not significantly different $(\mathrm{p}=0.111)$. The contralateral (non-lesioned) side was not significantly different between thrombin and saline groups $(\mathrm{p} \geq 0.111)$. Thus, thrombin infusion significantly and substantially reduced dendritic length and number of branches in the surviving neurons in peri-lesion zone, as we had predicted. The saline control infusion had minimal effects on dendritic structure.

\section{Experiment 2}

As noted, infusing $30 \mu \mathrm{L}$ of saline does not cause striatal injury beyond the needle tract. Here we also show that infusing heatinactivated thrombin in $30 \mu \mathrm{L}$ of saline also does not cause injury beyond the needle tract (Fig. 4A). In contrast, thrombin caused moderate and obvious damage to the striatum as seen at 7 (Fig. 4B) and 60 days post-infusion (Fig. 4C). There was also some damage to the corpus callosum at these times. The area of injury (abnormal looking tissue and areas of cell death) declined over time while the ventricle ipsilateral to the lesion expanded (ventriculomegaly). The total volume of tissue lost, which includes for ventricular dilation, was approximately $25 \mathrm{~mm}^{3}$ and not significantly different between 7 and 60 days (Fig. 4D, p =0.803). This is in contrast to our initial prediction that thrombin would cause chronic injury culminating in lesion expansion over time.

\section{Discussion}

We report that an intracerebral infusion of thrombin causes acute cell death and the expected behavioral dysfunction, confirming the findings of others. ${ }^{13,15,21,22}$ Those studies, however, 
(a)

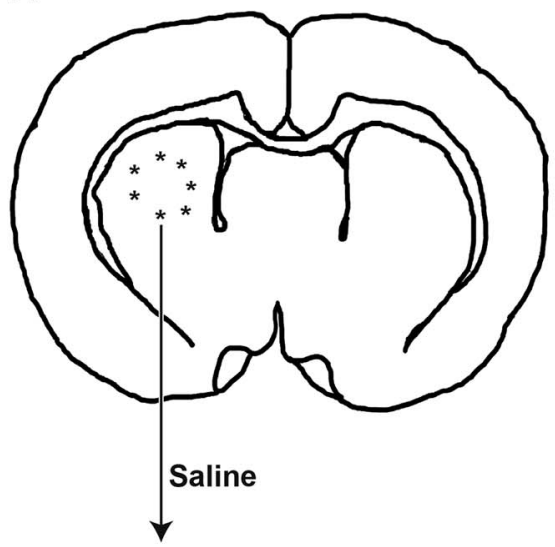

(b)

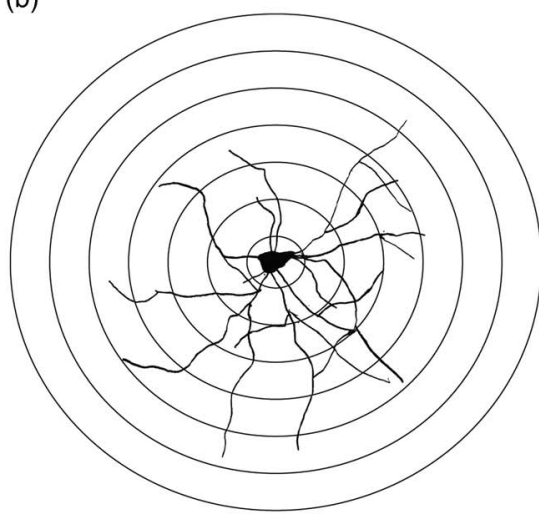

(c)

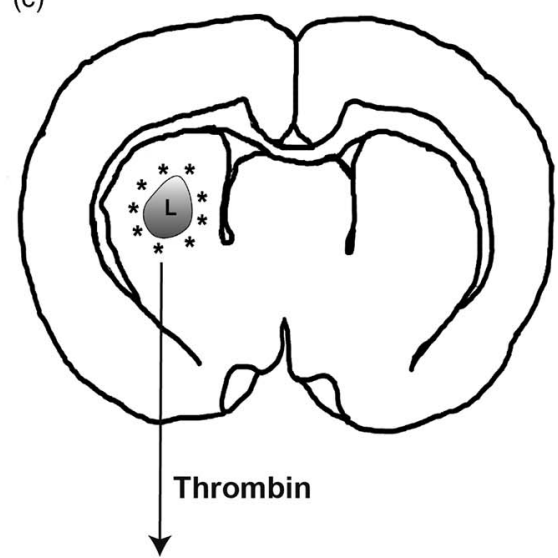

(d)

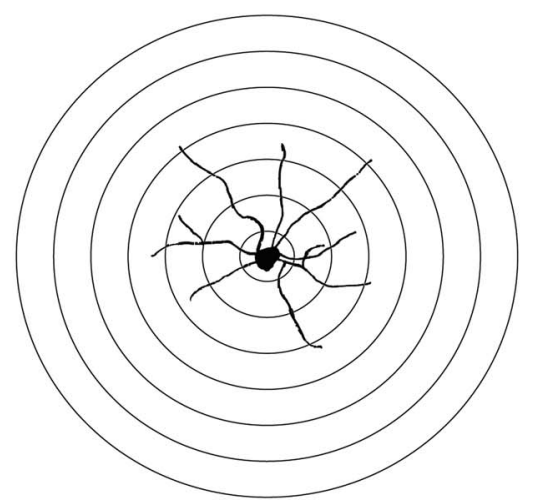

Figure 2: An illustration of the location of Golgi-Cox stained neurons drawn from A) saline and $C$ ) thrombin infused rats. The lesion is denoted by ' $L$ ' whereas an * indicates the approximate location of cells that were drawn. Cells in the contralateral striatum were also drawn in both groups (not illustrated). B) Representative drawing of normal cell in the saline treated group. D) Representative neuron from a thrombin infused rat. Neurons were hand drawn (camera lucida method) and all cells were assessed at the same magnification. A layer of concentric circles is then placed over the hand drawn neurons, shown in $B$ and $D$, which is the Sholl analysis method to assess dendritic length (i.e., counts of the number of intersections with rings). Note that the distance between concentric rings is $25 \mu \mathrm{m}$ when drawn using a $20 \times$ objective. Thus, the number of circle crossings can be used to calculate total dendritic length (Fig. 3).

generally focused on acute cell death and did not evaluate the time course of injury, which is of therapeutic importance for identifying and refining potential neuroprotective strategies suitable for the sub-acute and chronic period. Thus we compared 7 and 60-day survival times and found that the total amount of brain injury is equivalent at these times. Thrombin alone did not cause significant chronic injury, unlike our previous findings with iron infusions. ${ }^{12}$ This suggests that iron, but not thrombin, contributes to the development of protracted secondary brain damage we reported to occur after a collagenase-induced $\mathrm{ICH}^{5,6}$

We also evaluated dendritic structure in surviving peri-lesion striatal neurons. Dendritic injury impairs synaptic communication and has been repeatedly linked to behavioral impairment after ischemic and hemorrhagic stroke. ${ }^{29}$ In this light, the remarkable loss of dendritic length and number of branches from surviving striatal neurons in the peri-lesion zone may only lead to further functional impairment beyond that caused by thrombin-induced cell death. These data also strongly implicate thrombin production as an important cause of acute peri-hematoma dendritic injury after $\mathrm{ICH}$, which we previously documented. ${ }^{6}$ An interesting consequence of these effects is that treatments that promote thrombin production to limit hematoma expansion, such as $\mathrm{rFVIIa}^{30}$ might counterproductively increase peri-hematoma cell death and atrophy thereby negating the beneficial effects of reducing hematoma size.

Our study has a number of limitations and future directions that should be considered. First, we infused a $1 \mathrm{U}$ bolus of thrombin in saline. For comparison, a $100-\mu \mathrm{L}$ bleed, which is commonly infused to model ICH in rodents, ${ }^{31,32}$ can produce about $30 \mathrm{U}$ of thrombin. This is a far greater amount than what we infused here and than that required to naturally induce clotting. ${ }^{15}$ Interestingly, with the rat thrombin presently used, our pilot work indicated that doses of $5 \mathrm{U}$ would cause severe injury and sometimes the animal's death whereas a $100-\mu \mathrm{L}$ infusion of whole blood is less damaging and rarely lethal in rat. While thrombin is quickly produced after an ICH (minutes), the temporal and spatial 


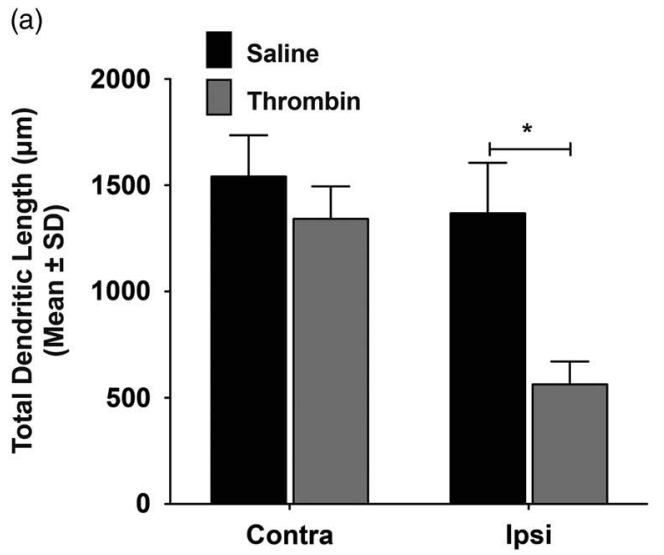

(b)

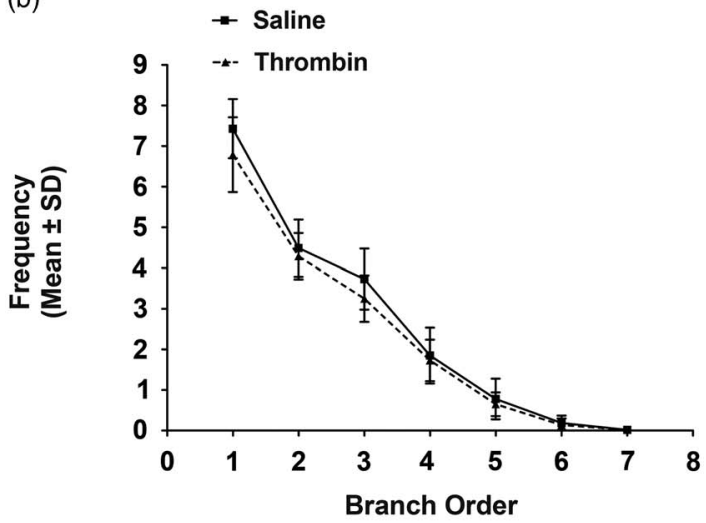

(c)

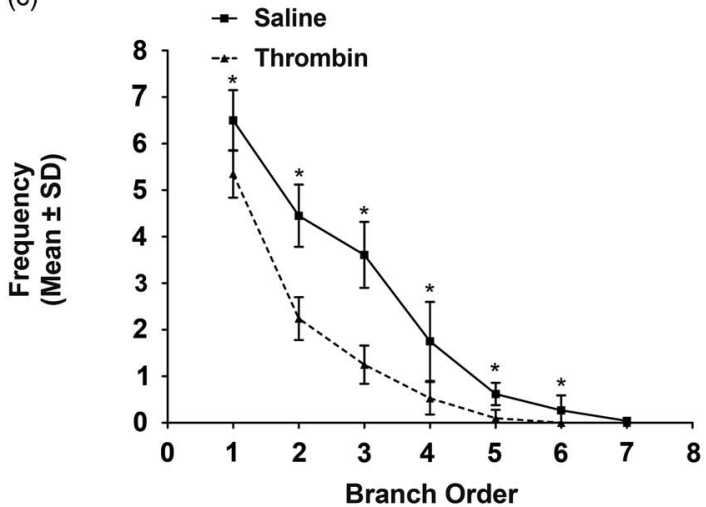

Figure 3: A) Total dendritic length determined from a Sholl analysis of neurons drawn from saline and thrombin treated rats. Length was determined by multiplying the number of circle crossings by the distance between circles (concentric circles are $25 \mu \mathrm{m}$ apart with the $20 \times$ objective used as illustrated in Fig. $2 B$ and D). Thrombin caused a substantial loss of dendritic branches in the peri-lesion zone that was more prominent closer to the lesion. There was no effect of saline infusion on the contralateral (normal) hemisphere. Branch order analysis (1st, 2nd, etc.), which is another measure of dendritic complexity, showed no group differences in the normal hemisphere $(B)$ whereas the number of branches was considerably reduced in the peri-lesion zone $(C)$. An $*$ denotes $p<0.05$.

distribution of thrombin would differ somewhat from that currently used. Specifically, the infused thrombin may more rapidly make contact with brain tissue. As well, some of the thrombin naturally produced may remain within the hematoma and not make contact with brain cells. Thus, the actual amount of thrombin coming in contact with brain may be greater in the present model than after the bleed typically used in ICH models. Other factors present in blood (e.g. anti-thrombin-III), but not in our infusion solution, would also limit thrombin's harmful activity in natural bleeding. All of these reasons help explain the apparent increase in toxicity of infused thrombin, which potentially limits the generalizability of our findings. Thus, we acknowledge the limitations of using a reductionist approach (infusing only thrombin at a low dose) and note that this paradigm has, nonetheless, been previously used to demonstrate the importance of thrombin and other agents (hemoglobin, iron, etc.) in ICH.

Second, we did not study the potential mechanisms by which thrombin caused cell death, such as increased production of pro-inflammatory cytokines, which others have studied extensively, as reviewed. ${ }^{11,16}$ We also did not study how thrombin causes dendritic damage and whether this qualitatively (different mechanisms), or quantitatively (dose effects), differs from the mechanisms of cell death. It is possible that dendritic damage may also simply be a downstream consequence of cell death (e.g., infiltration of inflammatory cells). In the current study, however, the observation of damaged neurons well beyond the inflammatory cells surrounding the lesion suggests that separate mechanisms may be involved. Additional studies using thrombin receptor agonists and antagonists (e.g., activating and scrambled peptides as in reference 33) would help tease apart these issues (e.g., receptor specificity). Finally, while it is conceivable that peri-hematoma dendritic atrophy ${ }^{6}$ results from mechanical forces (primary damage) after ICH, such a mechanism is unlikely after thrombin (in saline) infusion. Notably, an infusion of the same volume of saline had minimal effects on dendritic structure (vs. contralateral side) or behavior and the atrophied neurons after thrombin infusion were also obvious even at considerable distances from the lesion. Instead, in vitro work suggests that thrombin, even at low doses, causes dendritic shortening $^{34-36}$ and so it is likely that the dendritic atrophy observed here was at least partially a direct consequence of thrombin. This makes dendritic arborization a reasonable therapeutic target to improve recovery and a logical endpoint to gauge efficacy in future neuroprotection and rehabilitation studies.

Third, we cannot determine the relative contributions of cell death, dendritic atrophy or other effects of thrombin on behavioral dysfunction. ICH studies using thrombin inhibitors to limit cell death and edema ${ }^{11,16}$ likely also mitigate dendritic damage and thus they are not able to tease apart the various contributors to improved behavioural recovery. Regardless, it is difficult to argue that the extensive atrophy observed here would not contribute significantly to behavioural impairment. Likewise, resolution of this atrophy, which we did not assess, may contribute to functional recovery as argued for $\mathrm{ICH}$ and other injuries. ${ }^{6,29,37}$ At least for striatal $\mathrm{ICH}$, dendritic injury appears to resolve over weeks ${ }^{6}$, which coincides with the typical behavioral recovery seen. ${ }^{28}$ The present histological method does not allow one to track individual neurons or branch specific changes over time, which is possible with 2-photon microscopy of cortical neurons. ${ }^{29,38}$ Future studies using cortical ICH and 2-photon microscopy would be able to study these issues and determine the time course of recovery as well as thresholds of injury (and hematoma size) beyond which delayed cell death occurs. As well, this approach could better determine how far atrophy extends by tracking individual cells at defined distances from the hematoma's border, which would add 
(a)

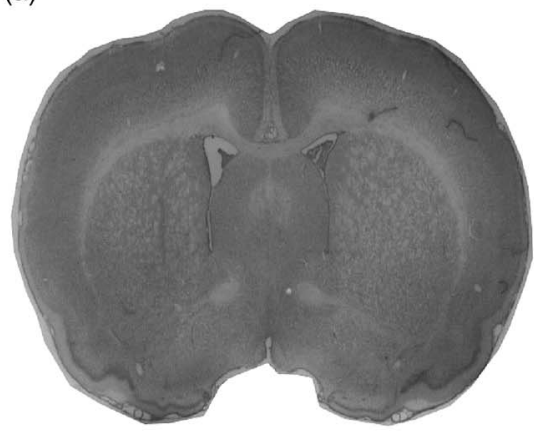

(c)

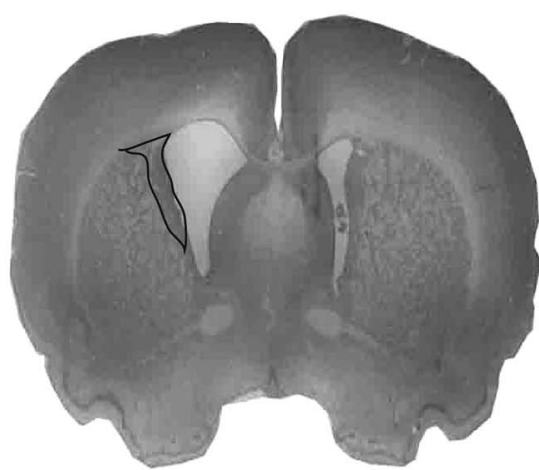

(b)

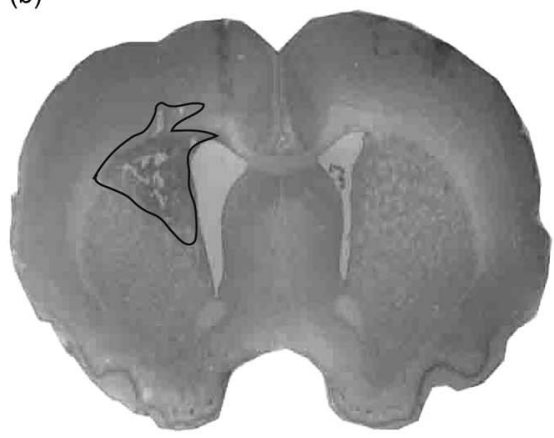

(d)

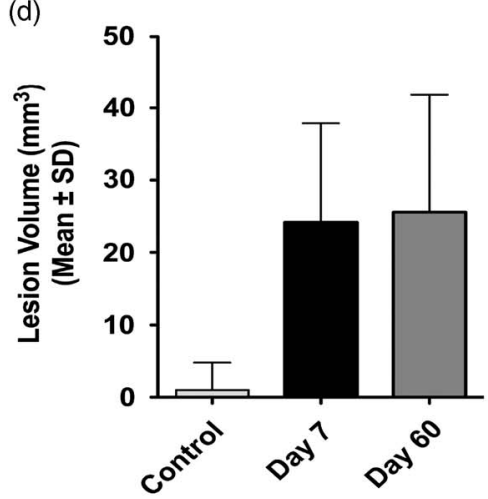

(e)

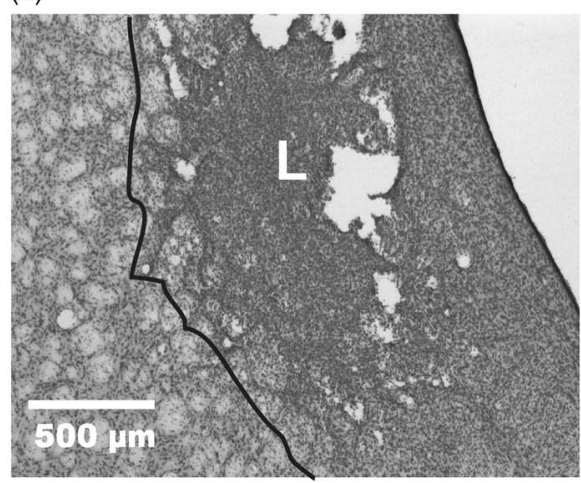

Figure 4: Representative photomicrographs showing the typical injury at 7 days following the infusion of heat-inactivated thrombin - "Control" (A). Only a needle tract is visible with no apparent additional damage. Infusion of active thrombin caused obvious injury at 7 (B) and 60-day $(C)$ survival times. A black line demarcates the lesion zone. Note that the residual lesion zone (dead tissue) shrinks with time leading to ventriculomegaly, which is evident in $B$ and especially $C$ (compare sides). There was no significant difference in average lesion volume between these days (D). Lesion volume is determined by subtracting the volume of the injured hemisphere from that of the normal side, and this includes the effects of ventriculomegaly. Our quantification method uses NIH ImageJ software to delineate normal from damaged tissue on scanned brain sections. This is also illustrated in a photomicrograph $(4 \times$ objective magnification) taken from a rat at 7 days following thrombin infusion (E). The blank line demarcates the transition zone from normal looking striatum to the lesion ("L"). For reference, the ventricle is at the upper right side. An investigator blinded to group identity quantified all images.

to our findings of a significant correlation between distance to lesion edge and dendritic length (cells near the lesion had smaller dendrites).

Fourth, a small amount of chronic cell death may have gone unnoticed because the assessment of total lesion volume over time, which we used, would not be able to detect subtle changes in lesion size. Nonetheless, this standardized and widely accepted approach was sensitive to the chronic cell death found after iron infusion $^{12}$ and in the collagenase model of $\mathrm{ICH}^{6}$

In summary, our study shows that intra-striatal thrombin infusion led to substantial dendritic damage and acute tissue loss but did not result in protracted secondary brain injury in rat. Therefore, these 
findings support a harmful role of thrombin in the acute period after $\mathrm{ICH}$, both in causing cell death, edema, blood brain barrier damage, etc., and in causing a dramatic loss of dendritic complexity (number of branches and their length) in surviving neurons in the peri-lesion area. After an ICH similar dendritic injury occurs, and thus this appears to be a suitable therapeutic target as well as a useful endpoint to gauge treatment efficacy.

\section{ACKNOWLEDGEMENTS}

Research support to F. Colbourne provided by the Heart and Stroke Foundation of Canada; Alberta Innovates - Senior Medical Scholar Award and a Canada Research Chair award. The authors thank Shannon Wowk and Crystal MacLellan for helpful comments on the manuscript, and Joelle Bristol and Elena Nicoladis for translating our abstract.

\section{REFERENCES}

1. Sacco S, Marini C, Toni D, Olivieri L, Carolei A. Incidence and 10 -year survival of intracerebral hemorrhage in a populationbased registry. Stroke. 2009;40(2):394-9.

2. Jorgensen HS, Nakayama H, Raaschou HO, Olsen TS. Intracerebral hemorrhage versus infarction: stroke severity, risk factors, and prognosis. Ann Neurol. 1995;38(1):45-50.

3. Frantzias J, Sena ES, Macleod MR, Al-Shahi Salman R. Treatment of intracerebral hemorrhage in animal models: meta-analysis. Ann Neurol. 2011;69(2):389-99.

4. DelBigio MR, Yan HJ, Buist R, Peeling J. Experimental intracerebral hemorrhage in rats. Magnetic resonance imaging and histopathological correlates. Stroke. 1996;27(12):2312-9.

5. MacLellan CL, Silasi G, Poon CC, et al. Intracerebral hemorrhage models in rat: comparing collagenase to blood infusion. J Cereb Blood Flow Metab. 2008;28:516-25.

6. Nguyen AP, Huynh HD, Sjovold SB, Colbourne F. Progressive brain damage and alterations in dendritic arborization after collagenaseinduced intracerebral hemorrhage in rats. Curr Neurovasc Res. 2008;5(3):171-7.

7. Skriver EB, Olsen TS. Tissue damage at computed tomography following resolution of intracerebral hematomas. Acta Radiol Diagn (Stockh). 1986;27(5):495-500.

8. Wu J, Hua Y, Keep RF, Nakamura T, Hoff JT, Xi G. Iron and ironhandling proteins in the brain after intracerebral hemorrhage. Stroke. 2003;34(12):2964-9.

9. Auriat AM, Silasi G, Wei Z, et al. Ferric iron chelation lowers brain iron levels after intracerebral hemorrhage in rats but does not improve outcome. Exp Neurol. 2012;234:136-43.

10. Caliaperumal J, Colbourne F. Rehabilitation improves behavioral recovery and lessens cell death without affecting iron, ferritin, transferrin, or inflammation after intracerebral hemorrhage in rats. Neurorehabil Neural Repair. 2014;28:395-404.

11. Keep RF, Hua Y, Xi G. Intracerebral haemorrhage: mechanisms of injury and therapeutic targets. Lancet Neurol. 2012;11(8): 720-731.

12. Caliaperumal J, Ma Y, Colbourne F. Intra-parenchymal ferrous iron infusion causes neuronal atrophy, cell death and progressive tissue loss: implications for intracerebral hemorrhage. Exp Neurol. 2012;15:363-9.

13. Gong $\mathrm{Y}, \mathrm{Xi} \mathrm{G}, \mathrm{Hu} \mathrm{H}$, et al. Increase in brain thrombin activity after experimental intracerebral hemorrhage. Acta Neurochir Suppl. 2008; $105: 47-50$.

14. Xue M, Hollenberg MD, Demchuk A, Yong VW. Relative importance of proteinase-activated receptor-1 versus matrix metalloproteinases in intracerebral hemorrhage-mediated neurotoxicity in mice. Stroke. 2009;40(6):2199-204.

15. Lee KR, Colon GP, Betz AL, Keep RF, Kim S, Hoff JT. Edema from intracerebral hemorrhage: the role of thrombin. J Neurosurg. 1996;84(1):91-6.

16. Babu R, Bagley JH, Di C, Friedman AH, Adamson C. Thrombin and hemin as central factors in the mechanisms of intracerebral hemorrhage-induced secondary brain injury and as potential targets for intervention. Neurosurg Focus. 2012;32(4):E8.

17. Striggow F, Riek M, Breder J, Henrich-Noack P, Reymann KG, Reiser $\mathrm{G}$. The protease thrombin is an endogenous mediator of hippocampal neuroprotection against ischemia at low concentrations but causes degeneration at high concentrations. Proc Natl Acad Sci U S A. 2000;97(5):2264-9.

18. Vaughan PJ, Pike CJ, Cotman CW, Cunningham DD. Thrombin receptor activation protects neurons and astrocytes from cell death produced by environmental insults. J Neurosci. 1995;15(7 Pt 2): $5389-5401$

19. Jiang $\mathrm{Y}, \mathrm{Wu} \mathrm{J}$, Hua $\mathrm{Y}$, et al. Thrombin-receptor activation and thrombin-induced brain tolerance. J Cereb Blood Flow Metab. 2002;22(4):404-10.

20. Yang S, Song S, Hua Y, Nakamura T, Keep RF, Xi G. Effects of thrombin on neurogenesis after intracerebral hemorrhage. Stroke. 2008;39(7):2079-84

21. Lee KR, Kawai N, Kim S, Sagher O, Hoff JT. Mechanisms of edema formation after intracerebral hemorrhage: effects of thrombin on cerebral blood flow, blood-brain barrier permeability, and cell survival in a rat model. J Neurosurg. 1997;86(2):272-8.

22. Xue M, DelBigio MR. Acute tissue damage after injections of thrombin and plasmin into rat striatum. Stroke. 2001;32(9):2164-9.

23. Xue M, DelBigio MR. Injections of blood, thrombin, and plasminogen more severely damage neonatal mouse brain than mature mouse brain. Brain Pathol. 2005;15(4):273-80.

24. Schallert T. Behavioral tests for preclinical intervention assessment. NeuroRx. 2006;3(4):497-504

25. Gibb R, Kolb B. A method for vibratome sectioning of Golgi-Cox stained whole rat brain. J Neurosci Meth. 1998;79:1-4.

26. MacLellan CL, Plummer N, Silasi G, Auriat AM, Colbourne F. Rehabilitation promotes recovery after whole blood-induced intracerebral hemorrhage in rats. Neurorehabil Neural Repair. 2011;25(5):477-83.

27. DeBow SB, Davies ML, Clarke HL, Colbourne F. Constraintinduced movement therapy and rehabilitation exercises lessen motor deficits and volume of brain injury after striatal hemorrhagic stroke in rats. Stroke. 2003;34(4):1021-6.

28. MacLellan CL, Auriat AM, McGie SC, et al. Gauging recovery after hemorrhagic stroke in rats: implications for cytoprotection studies. J Cereb Blood Flow Metab. 2006;26:1031-42.

29. Murphy TH, Corbett D. Plasticity during stroke recovery: from synapse to behaviour. Nat Rev Neurosci. 2009;10(12):861-72.

30. Mayer SA, Brun NC, Begtrup K, et al. Efficacy and safety of recombinant activated factor VII for acute intracerebral hemorrhage. N Engl J Med. 2008;358(20):2127-37.

31. Bullock R, Mendelow AD, Teasdale GM, Graham DI. Intracranial haemorrhage induced at arterial pressure in the rat. Part 1: Description of technique, ICP changes and neuropathological findings. Neurol Res. 1984;6(4):184-8.

32. MacLellan CL, Paquette R, Colbourne F. A critical appraisal of experimental intracerebral hemorrhage research. J Cereb Blood Flow Metab. 2012;32:612-7.

33. Vu TK, Hung DT, Wheaton VI, Coughlin SR. Molecular cloning of a functional thrombin receptor reveals a novel proteolytic mechanism of receptor activation. Cell. 1991;64(6):1057-68.

34. Cunningham DD, Gurwitz D. Proteolytic regulation of neurite outgrowth from neuroblastoma cells by thrombin and protease nexin-1. J Cell Biochem. 1989;39(1):55-64.

35. Gurwitz D, Cunningham DD. Thrombin modulates and reverses neuroblastoma neurite outgrowth. Proc Natl Acad Sci U S A. 1988;85(10):3440-4

36. Gurwitz D, Cunningham DD. Neurite outgrowth activity of protease nexin-1 on neuroblastoma cells requires thrombin inhibition. J Cell Physiol. 1990;142(1):155-62.

37. Auriat AM, Wowk S, Colbourne F. Rehabilitation after intracerebral hemorrhage in rats improves recovery with enhanced dendritic complexity but no effect on cell proliferation. Behav Brain Res. 2010;214:42-7.

38. Brown CE, Boyd JD, Murphy TH. Longitudinal in vivo imaging reveals balanced and branch-specific remodeling of mature cortical pyramidal dendritic arbors after stroke. J Cereb Blood Flow Metab. 2010;30(4):783-91. 